医学図書館 $32(3): 298-302,1985$

パソコンの基礎的知識

\section{Basic Knowledge for Personal Computers (4)}

清 水悟*

東京女子医科大学衛生学教室

(4)

\section{BASIC 文法上の注意点}

前号では BASIC 言語によるプログラミングと実行 について述べたが，今回はプログラミングにおける BASIC 文法上, 特に重要と思われる概念について述べ ることにする。

BASIC 言語のくわしい文法に関しては, 多数の刊行 物があるので，それを利用されたい。

\section{I. 定数と変数}

定数とはプログラムの実行時に，そのまま使用する 值のことである。その場合, 数值定数と文字定数があ る。

$10 \triangle$ PRINT $10.0 \ldots \ldots . . .$. 数值定数
$20 \triangle$ PRINT $\quad 10.0^{\prime \prime} \cdots \cdots$. 文字定数
$30 \triangle$ END

このプログラムを実行させた場合, 文番号 10 と文番 号20のプリント命令によって，どちらの場合ともディ スプレイには，

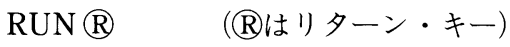

10

10.0

\footnotetext{
* Satoru SHIMIZU : Tokyo Women's Medical College, Department of Hygiene. 10 Kawada-cho, Ichigaya, Shinjuku-ku, Tokyo 162, Japan.

(昭和 60 年 8 月 19 日 受理)
}

とプリントされる。しかしながら両者の意味は異な る。つまり文番号10の場合, 数值定数をプリント(ディ スプレイ上に…）したのに対して文番号20では文字を プリントしたのである。前者の場合は計算式（コン ピュータのプログラム上では代入文）の中でも，数值 としての意味を持つが, 後者の文字定数の場合はあく までも「文字」としての意味であって，計算式の中に 組み込むとエラーとなる。つまり，ダブルコーティー ションによって囲まれた場合, 我々が日常数值と呼ぶ ものであっても文字定数あるいは一連の文字列と見な される。

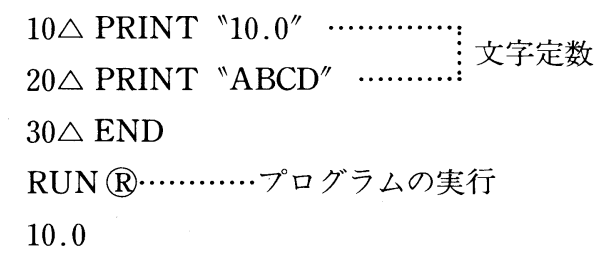

$\mathrm{ABCD}$

以上のような文字と数值の区別は変数についても存 在する。変数とはプログラムのなかで使う值（文字列 や数值) を格納しておく場所の名前である。たとえて 言えば，たくさんの小引出しを机の前に無数に置いて おき，必要な時に数值や文字を紙にメモして入れてお く。ただしその引き出しには自分で識別できるように 紙に名前をつけて貼って扔き，次に必要になった時に それを取り出すようにしておくものである。利用でき る変数の数は，始めに用意した“引き出し”の数によっ て決まる。つまりコンピュータのメイン・メモリーの 大きさによって決まる訳である。さらに同じ名前を複 
数の “引き出し"につけると，あとで取り出すときに 混乱を引きおこすことになるので禁止されなければな らない。また変数に対する名前をつける場合，いくつ かの制限があるが，機種によって，その制限は異なる 場合が多いので共通する事項を次に上げてみる。

(1)変数名は英字及び数字で表されるが，その使用で きる文字数には限界がある。普通は $6 \sim 8$ 文字以 内（古い機種では英数字 2 文字までしか許されな いものもある)，その場合，先頭の 1 文字は英字で あること。

(2)文字変数には，特定な記号を後につける場合があ る。

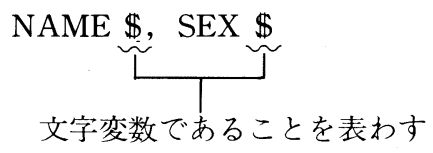

(3) BASIC 言語で使われる命令や文と同一の名前で あってはならない。

PRINT ……変数名として使えない。

PRINTX …変数名として使える。

XPRINT …. "

以上のような制限は各機種の BASIC 言語に共通し ている。さらに数值変数については, 整数型変数と実 数型変数, また表現できる有効桁数の違いによる単精 度型と倍精度型という様な区分があるが，くわしくは BASIC 文法書を参照されたい。

実際の計算式をプログラミングする場合は我々が日 常用いる計算式と少しばかり違うところは, BASICの 場合代入文を用いるところである。

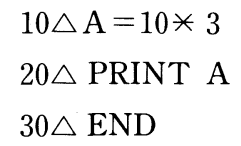

このプログラムを実行させた場合, ディスプレイに は

\section{RUN $\mathbb{R}$}

30 .計算結果
となるが,ここで注意すべき点は文番号10である。"=" は通常の計算式で用いる等号であり, “*”は積を表わ す演算子であるが，プログラム及び結果から想像でき るとおり，右辺の計算結果を左辺の変数 $\mathrm{A} に$ 代入して いる。この様に BASICの計算式は右辺の計算結果を 左辺の変数に代入するという原則を持つ。したがって 以下の様に左辺に複数の変数があってはならないこと になる。

$$
\begin{gathered}
\mathrm{A}+\mathrm{B}=10.0 * 3 \cdots \cdots \cdot(\text { 左辺において代入すべき変数 } \\
\text { が識別できない })
\end{gathered}
$$

つぎに以下のプログラムに注目すると，

$$
\begin{aligned}
& 10 \triangle \mathrm{A}=31.5 \\
& 20 \triangle \mathrm{A}=\mathrm{A}+20.0
\end{aligned}
$$

\section{$30 \triangle$ PRINT A}

$40 \triangle \mathrm{END}$

このプログラムを実行させると

RUN $\cap$

$41.5 \cdots \cdots \cdots \cdots . . . . . .$. 計算結果

以上のことから同一変数が左右両辺にある場合に は, 同一変数であっても右辺の変数はその文番号以前 に定義された值を保持している。さらにその右辺の計 算結果が新たに左辺の変数の值となる。また原則とし て同一プログラムにおいては，変数に対して何らかの 処理をしない限り，最後に代入された值を変数は保持 し続ける。よく期待した計算結果がでない場合，他の プログラム行でその変数に予期しない值が代入されて いる場合が多いので注意を要する。

つぎに計算式で使う演算子について触れておくが, 機種によって多少, 演算子として使れる特殊記号に違 いがある場合がある。

$$
\begin{aligned}
& 10 \triangle \mathrm{A}=\mathrm{B} * \mathrm{C} / \mathrm{D} \\
& 20 \triangle \mathrm{AA}=\mathrm{BB}+(\mathrm{CC}-\mathrm{DD}) / \mathrm{EE}
\end{aligned}
$$


$30 \triangle \mathrm{AAA}=\mathrm{BB} \wedge \mathrm{C}$

この場合，演算子として使われている「*」は乗法， 「／」は除法を表わし，さらに「へ」はべき乗を表わ す（文番号30では変数 Cがべき乗の指数を表わす。ま た「(」,「)」を用いてくくった場合, 一般の計算式と 同様な計算順位の意味を持つ。

II. 関 数

プログラムの計算式 (代入文) の中で平方根, 対数, ……などを求めることが必要になる場合があるが，そ の場合にはBASIC言語では関数と呼ばれる命令がある。

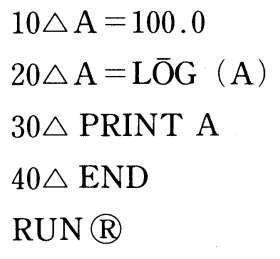

$2 \cdots \cdots \cdots \cdots$ 計算結果

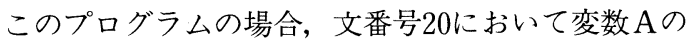
対数 $\left(\log _{10} A\right)$ を求めて, 左辺の変数 Aにまた代入し ている。この様な関数が用意されているので，必要な 都度，プログラム中で使用できる。おもな関数として は次表参照。

数値関数 $\mathrm{x}$ は数式、Sは文字式とする

\begin{tabular}{|c|c|c|}
\hline 时 & 静 & 佛 \\
\hline ABS $(x)$ & xの福対㗹を与える & PRINT ABS $(-40) は 40$ \\
\hline 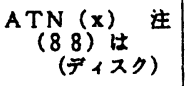 & $\begin{array}{l}\text { xのアークタンジェント } \\
\text { 結果はラシナシ }\end{array}$ & 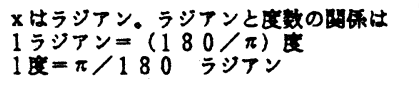 \\
\hline CDBL $(x)$ & 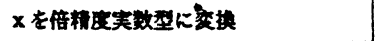 & $A \#=C D B L \quad(B)$ \\
\hline CINT $(x)$ & x を证数型に交挨 & $\begin{array}{l}\text { xの傗の小数点以下は、四搭五入する } \\
-32768 \leq 32767\end{array}$ \\
\hline $\cos (x)$ 注 & xのコサイン & xはラジアン \\
\hline $\operatorname{csNG}(x)$ & 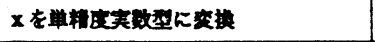 & $A=\operatorname{CSNG}(C+2)$ \\
\hline CVD (S) & 8 パイトの文字列を倍精度の数值に费 & 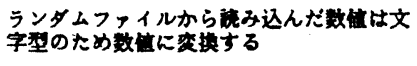 \\
\hline Cvs (s) & 4 パイトの文字列を單䊒度の数偣に交 & $\begin{array}{lll}1 & 0 & \text { FIELD\# } 1,4 \text { AS A } \$ \cdots \\
2 & 0 & \text { GET } \# 1 \\
3 & & \end{array}$ \\
\hline CVI (S) & 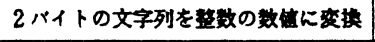 & \\
\hline $\operatorname{EXP}(x)$ 注 & eのx乘 & 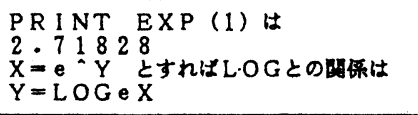 \\
\hline$F I X(x)$ & 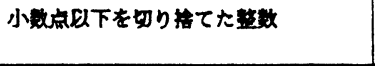 & $\begin{array}{lll}\text { PRINT } & \text { FIX }(4 \cdot 56) & \text { は } 4 \\
\text { PRINT } & \text { FIX }(-4.5) & \text { は }-4\end{array}$ \\
\hline I NT $(x)$ & xを眧えない最大の亘数 & $\begin{array}{lll}\text { PRINT } & \text { INT }(4 ; 56) & \text { は } 4 \\
\text { PRINT } & \text { INT }(-4.5) & \text { I }-5\end{array}$ \\
\hline LOG $(x)$ 注 & xの自然対妏 & $\begin{array}{l}x>0 \text { とする。自然対数を常用対数にする } \\
\text { 式はLOG }(x) / L O G\left(\begin{array}{ll}1 & 0\end{array}\right)\end{array}$ \\
\hline RND（x） 注 & 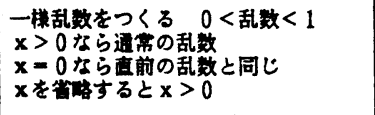 & 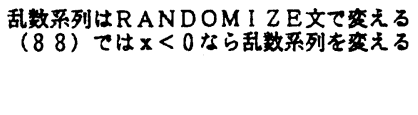 \\
\hline $\operatorname{SGN}(x)$ & xの正青将号を与える & 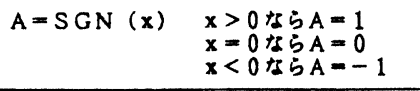 \\
\hline SIN（x) 注 & xのサイン & x はラシアン \\
\hline $\operatorname{SQR}(x)$ 注 & xの平方根 & $x \geq 0$ であること \\
\hline TAN (x) 注 & xのタンジェント & xはラシアン \\
\hline
\end{tabular}


清水：パソコンの基礎的知識 301

\section{III. 文字の取り扱い}

コンピュータを使用する目的を，安易に「複雑な計 算の為」ばかりと規定することは，パソコンといえど も「汎用情報処理機」という範疇に入ることを忘れる ことになる。数值計算だけならば，処理するデー夕件 数が少い場合には電卓の方がはるかに早い。パソコン はいちいちプログラミングをしなければならないから である。しかし，こと一連文字群（文字列，文章など も含む)の処理に関しては電卓などでは処理できない。 また日常業務でも文字に関する処理が多く，この方面 にパソコンを利用する主目標がある訳である。

まず文字列（一連の文字群）の演算について述べる が，文字同士の演算と聞くと何か違和感を覚える方が 多い。しかし数值と同様な四則演算は出来ないが, 加 法だけは可能である。まず以下のプログラムのように

$$
\begin{aligned}
& 10 \triangle \mathrm{A} \$=" \mathrm{ABC} \text { " } \\
& 20 \triangle B \$=~ " E F G " \\
& 30 \triangle \mathrm{C} \$=\mathrm{A} \$+\mathrm{B} \$ \\
& 40 \triangle \text { PRINT C } \$ \\
& 50 \triangle \mathrm{END} \\
& \text { RUN } ®
\end{aligned}
$$$$
\text { ABCDEF………実行結果 }
$$

このプログラムの場合，各変数についている「\$」 は文字変数であるということを示す。さらに文字列相 互の比較が可能である。つまり，二つの文字列変数に 含まれる文字列が等しいかどうかを比較できる。これ は特に後述する条件分岐命令 $(\mathrm{IF}-\mathrm{THEN}-)$ との組 み合せで用いることが多い。

以下に文字列に関する関数（ストリング関数）を示 すが，これは文字列に対して有効であり，数值変数に 用いるとエラーとなる。よくある䛊りとして，数值変 数と文字変数の混合使用があげられる。

\section{IV. 配 列}

BASIC 言語を学ぶ上で,よく頭を痛める項目がこの
配列の使用である。たとえばプログラムの中で

$10 \triangle \mathrm{DIM} \quad \mathrm{A}(10)$

という文があった場合，Aという10個（実際は 0 ～10 までの11個）の引き出しを持ったキャビネットを想像 すればよい。

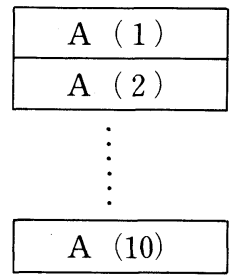

この例は 1 次元の配列であるが，2 次元の配列の場 合は,

$10 \triangle \mathrm{DIM} \quad \mathrm{B}(10,10)$

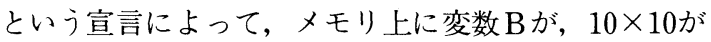
引き出しを持ったキャビネットのように定義される。

配列の参照方法は, 配列名のあとの「(」,「)」の中 に何番目の “引き出し”を使用するか整数值あるいは 整数值を含む変数を指定することで使用することがで きる。

$10 \triangle \mathrm{DIM} \quad \mathrm{A}(10,10)$

$20 \triangle \mathrm{A}(1,3)=10.5$

$30 \triangle \mathrm{I}=2$

$40 \triangle \mathrm{J}=3$

$50 \triangle \mathrm{A} \quad(\mathrm{I}, \mathrm{J})=15.5$

$60 \triangle$ PRINT A $(1,3), \mathrm{A}(2,3)$

RUN $®$

$10.5 \quad 15.5 \cdots \cdots \cdots \cdots \cdot$. 実行結果

このプログラムのように配列名に続けて「(」,「)」, の中で使用する配列の要素の位置を示すものを添字と 呼ぶ。配列宣言による配列要素の数は使用できるメモ リーの領域によって制限される。また 2 次元配列など 
ストリング関数

$\mathrm{x} 、 \mathrm{n} 、 \mathrm{~m}$ は数式、 $\mathrm{S}$ は文字式とする

\begin{tabular}{|c|c|c|}
\hline 数 & 機 & 借 \\
\hline ASC (S) & $\begin{array}{l}\text { 文字列S の最初の文字のコードを数値 } \\
\text { でえる }\end{array}$ & 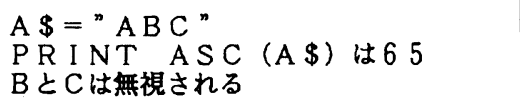 \\
\hline $\mathrm{CHR} \$(x)$ & コードxに対応する文字を & 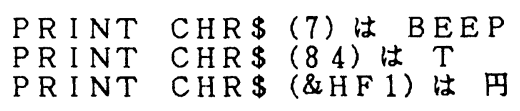 \\
\hline $\operatorname{HEX} \$(x)$ & $x$ の 16 進数文字列を与える & PRINT HEX\$(25 5) はFF \\
\hline I NKEY $\$$ & $\begin{array}{l}\text { キーボードが押さ } \\
\text { 押されればそのう }\end{array}$ & 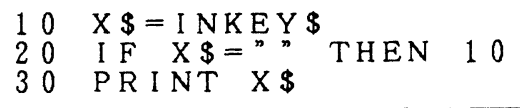 \\
\hline $\begin{array}{l}\text { I NSTR ( ( } \\
\text {, ) S } 1, S 2)\end{array}$ & 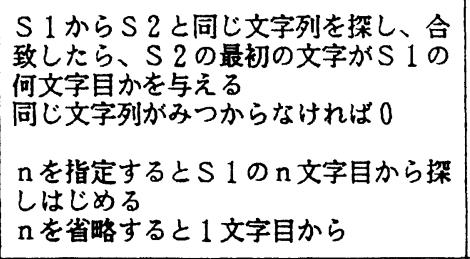 & 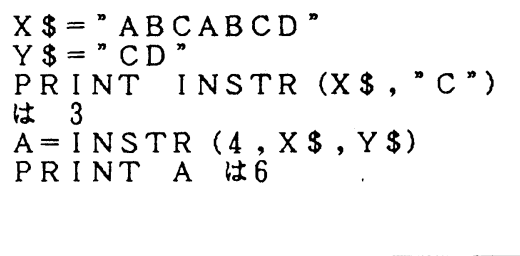 \\
\hline $\begin{array}{l}\operatorname{LEFT} \$ \\
\qquad(\mathrm{~S}, \mathrm{n})\end{array}$ & $\begin{array}{l}\text { Sの左からn 番目までの文字列を与え } \\
\text { る } \\
\mathrm{n} \text { は } 0 〜 255\end{array}$ & $\begin{array}{l}X \$=" A B C D E F " \\
P R I N T \text { LEFT } \$(X \$, 3) \text { は } \\
A B C\end{array}$ \\
\hline LEN (S) & $s$ & $\begin{array}{l}X \$=" A B C D E F " \\
\text { PRINT LEN (X\$)は } 6\end{array}$ \\
\hline $\begin{array}{l}\mathrm{M} I \mathrm{D} \$ \\
(\mathrm{~S}, \mathrm{n}, \mathrm{m})\end{array}$ & $\begin{array}{l}\text { Sの左 } \mathrm{n} \text { 文字目から長さ } \mathrm{m} \text { の文字列を } \\
\text { 与える } \\
\text { M I D \$ は代入文の左辺ても使うこと } \\
\text { ができる } \\
\text { Sの左n 文字目から長さ } \mathrm{m} \text { に右辺の文 } \\
\text { 字を入れる }\end{array}$ & 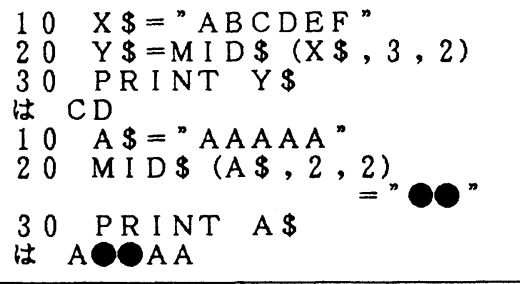 \\
\hline $\operatorname{MKD} \$(x)$ & $\begin{array}{l}\text { 倍精度実数 xを } 8 \text { バイトの文字列に変 } \\
\text { 稳する }\end{array}$ & \multirow{3}{*}{ 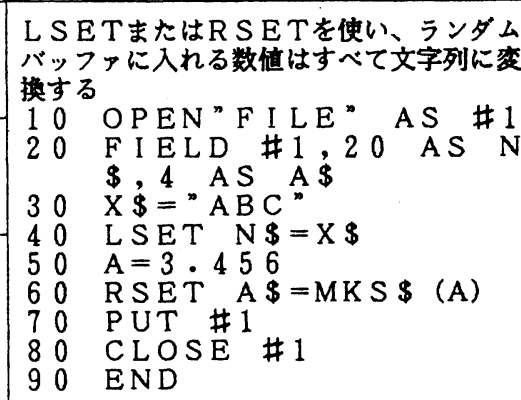 } \\
\hline MKS $\$(x)$ & $\begin{array}{l}\text { 単精度実数 } \mathrm{xを} 4 \text { バイトの文字列に变 } \\
\text { 換する }\end{array}$ & \\
\hline MKI $\$(x)$ & 整数 $\mathrm{x}$ を 2 バイトの文字列に変换する & \\
\hline
\end{tabular}

